\title{
Altered Microviscosity at Brain Membrane Surface Induces Distinct and Reversible Inhibition of Opioid Receptor Binding
}

\author{
Dan F. Lazar and Fedor Medzihradsky \\ Departments of Biological Chemistry and Pharmacology, University of Michigan Medical School, \\ Ann Arbor, Michigan, U.S.A.
}

\begin{abstract}
In synaptosomal membranes from rat and monkey brain cortex, the addition of petroselenic $\left(18: 1, c i s-\Delta^{6}\right)$ acid, oleic $\left(18: 1, c i s-\Delta^{9}\right)$ acid, and vaccenic $\left(18: 1\right.$, cis- $\left.\Delta^{11}\right)$ acid or their corresponding methyl esters at $0.5 \mu \mathrm{mol} / \mathrm{mg}$ of membrane protein caused a similar $7-10 \%$ decrease in the microviscosity of the membrane core, whereas at the membrane surface the microviscosity was reduced $5-7 \%$ by the fatty acids but only $1 \%$ by their methyl esters. Concomitantly, the fatty acids, but not the methyl esters, inhibited the specific binding of the tritiated $\mu-, \delta$, and $\kappa$-opioids TyrD-Ala-Gly-(Mc)Phe-Gly-ol (DAMGO), [D-Pen $\left.{ }^{2}, D_{-P e n}{ }^{5}\right]-$ cnkephalin (DPDPE), and U69,593, respectively. As shown with oleic acid, the sensitivity of opioid receptor binding toward inhibition by fatty acids was in the order $\delta>\mu \gg \kappa$, whereby the binding of $\left[{ }^{3} \mathrm{H}\right]$ DPDPE was abolished, but significant inhibition of $\left[{ }^{3} \mathrm{H}\right] \mathrm{U} 69,593$ binding, determined in membranes from monkey brain, required membrane modification with a twofold higher fatty acid concentration. Except for the unchanged $K_{\mathrm{D}}$ of $\left[{ }^{3} \mathrm{H}\right] \mathrm{U} 69,593$, the inhibition
\end{abstract}

by oleic acid involved both the $B_{\max }$ and affinity of opioid binding. Cholesteryl hemisuccinate $(0.5-3 \mu \mathrm{mol} / \mathrm{mg}$ of protein), added to membranes previously modified by fatty acids, reversed the fluidization caused by the latter compounds and restored inhibited $\mu-, \delta$, and $\kappa$-opioid binding toward control values. In particular, the $B_{\max }$ of $\left[{ }^{3} \mathrm{H}\right]-$ DPDPE binding completely recovered after being undetectable. The results implicate membrane surface fluidity in the modulation of opioid receptor binding, reveal distinct sensitivity of $\delta, \mu$, and $\kappa$ receptors toward that modulation, and identify unsaturated fatty acids and cholesterol as possible endogenous regulators of opioid receptor function. Key Words: $\mu$-, $\delta$-, and $\kappa$-opioid receptors-Fatty acids-Cholesterol-Membrane fluidity-Synaptosomal membranesFluorescence polarization. I azar D. F. and Medzihradsky F. Altered microviscosity at brain membrane surface induces distinct and reversible inhibition of opioid receptor binding. J. Neurochem. 59, 1233-1240 (1992).
The role of membrane environment in modulating the activity of intrinsic membrane proteins is well documented. Specifically, in numerous studies the function of membrane-bound enzymes, receptors, and transport carriers was correlated with membrane fluidity, a biophysical property largely determined by membrane composition at a given temperature (Aloia et al., 1988; Viret et al., 1990). The results of these studies have confirmed the significance of membrane fluidity as a parameter that affects the dynamics and thereby the biological activity of various membrane constituents. However, it has also been shown that modulation of membrane protein function may occur by the interaction of the proteins with distinct membrane lipids rather than as the result of an altered bulk property of the lipid bilayer (Carruthers and Melchior, 1986). The existence of opioid receptors in different membrane microenvironments was proposed (Maruyama et al., 1987), and the clustering of opioid receptors on cell surfaces, presumably as the result of lateral mobility in the membrane, has been described (Hazum et al., 1980). Although it was not measured, increased membrane fluidity was discussed as a phenomenon underlying the reduction of opioid binding in neuroblastoma $\times$ glioma cells grown in the presence of unsaturated fatty acids (Ho and Cox, 1982). On the other hand, the presence of specific lipids, rather than altered membrane fluidity, was postulated as a requirement for opioid receptor coupling to adenylate cyclase in rat brain membranes
Received October 22, 1991; revised manuscript received March 4, 1992; accepted March 23, 1992.

Address correspondence and reprint requests to Dr. F. Medzihradsky at the Department of Biological Chemistry, University of Michigan Medical School, Medical Science Building I, Ann Arbor, MI 48109-0606, U.S.A.
Abbreviations used: CHS, cholesteryl hemisuccinate; DAMGO, Tyr-D-Ala-Gly-(Me)Phe-Gly-ol; DPDPE, [D-Pen ${ }^{2}, D-P^{-}{ }^{5}$ ]enkephalin; DPH, diphenylhexatriene; $F \Lambda$, fatty acids; FAME, fatty acid methyl esters; PA-DPH, propionic acid-DPH; TMA-DPH, trimethylammonium-DPH. 
(Childers and LaRiviere, 1984). Altered binding of tritiated enkephalinamide binding in brain membranes of differing fluidity was first reported by Heron et al. (1981), and the sensitivity of the opioid receptor to effects of fatty acids was described earlier (Lin and Simon, 1978; McGee and Kenimer, 1982).

Recently we have shown that, at comparable membrane content, the cis isomers of monounsaturated fatty acids were more potent than their trans counterparts in inhibiting opioid binding and in increasing the fluidity of rat brain membranes (Remmers et al., 1990). Considering the results of that research and the proposed localization of the $\delta-, \mu$-, and $\kappa$-opioid receptors in membrane regions of different hydrophobicity and charge (Schwyzer, 1986; Schiller et al., 1989), the aim of the present study was to examine the mechanism underlying the potent effects of fatty acids on opioid binding, focusing thereby on the role of membrane domains and their fluidity. A brief account of this work was presented previously (Lazar et al., 1991).

\section{MATERIALS AND METHODS}

\section{Materials}

$\left[{ }^{3} \mathrm{IH}\right]$ Tyr-D-Ala-Gly-(Me)Phe-Gly-ol $\left(\left[{ }^{3} \mathrm{H}\right] \mathrm{DAMGO}\right)$ and $\left[{ }^{3} \mathrm{H}\right]\left(\mathrm{D}-\mathrm{Pen}^{2}, \mathrm{D}-\mathrm{Pen}^{5}\right)$ enkephalin $\left(\left[{ }^{3} \mathrm{H}\right] \mathrm{DPDPE}\right)$ were purchased from Amersham (Arlington Heights, IL, U.S.A.), whereas $\left[{ }^{3} \mathrm{H}\right] \mathrm{U} 69,593$ was obtained from New England Nuclear (Boston, MA, U.S.A.). All unlabeled opioids were supplicd by the Narcotic Drug and Opiate Peptide Basic Research Center at The University of Michigan. The fatty acids (FA) petroselenic (cis- $\Delta^{6}$-octadecenoic), oleic (cis- $\Delta^{9}$ octadecenoic), and vaccenic (cis- $\Delta^{11}$-octadecenoic), and their methyl esters were obtained from Serdary Laboratories (London, Ontario, Canada). Cholesteryl hemisuccinate (CHS) and other biochemicals were purchased from Sigma Chemical (St. Louis, MO, U.S.A.). Diphenylhexatriene (DPH), trimethylammonium-DPH (TMA-DPH), and propionic acid-DPH (PA-DPH) werc obtained from Molecular Probes (Junction City, OR, U.S.A.).

\section{Membrane preparation}

The synaptosomal preparation was obtained from brain cortices of male Sprague-Dawley rats or a rhesus monkey as described by Cahill and Medzihradsky (1976) and Clark et al. (1988). The preparation was thoroughly characterized by marker enzymes, ion content, and synaptosomal transport processes. The contamination by mitochondria was $<5 \%$ (Cahill and Medzihradsky, 1976). Membranes were isolated by hypotonic disruption in $50 \mathrm{~m} M$ Tris- $\mathrm{HCl}, \mathrm{pH} 7.4$, using a Dounce all-glass homogenizer. The obtained membrane suspension, at a protein concentration of approximately 3 $\mathrm{mg} / \mathrm{ml}$, was stored at $-80^{\circ} \mathrm{C}$. Protein was determined according to Lowry et al. (1951) using bovine serum albumin as standard. Prior to the determination, the membranes were solubilized with $1 \mathrm{M} \mathrm{NaOH}$ for $30 \mathrm{~min}$ at $25^{\circ} \mathrm{C}$.

\section{Membrane modifications}

FA, fatty acid methyl esters (FAME), or CHS was added to membrane suspensions as solutions in ethanol. Membranes were then incubated at $25^{\circ} \mathrm{C}$ for either $20 \mathrm{~min}$ (addition of FA or FAME) or 30 min (addition of CHS). In control experiments, membranes were incubated with ethanol alone. In experiments where the final ethanol concentration exceeded $0.5 \%$, the membranes were centrifuged for $15 \mathrm{~min}$ at $22,500 \mathrm{~g}$ and then resuspended in $50 \mathrm{mM}$ Tris- $\mathrm{HCl}$, $\mathrm{pH} 7.4$.

\section{Measurement of membrane microviscosity}

The fluorescent probe DPH (solution in tetrahydrofuran) and its cationic and anionic derivatives TMA-DPH and PA-DPH (solutions in $N, N$-dimethylformamide), respectively, were incubated with membranes at $25^{\circ} \mathrm{C}$. Fluorescence measurements were made with an SLM 8000 spectrofluorometer using excitation and emission wavelengths of $340 \mathrm{~nm}$ and $450 \mathrm{~nm}$, respectively. The results were expressed as anisotropy values $(r)$ where $r=\left(I_{0}-I_{90}\right) /\left(I_{0}\right.$ $-2 I_{90}$ ) and $I_{0}$ and $I_{90}$ represent the intensities of light when polarizers were in a parallel or perpendicular orientation, respectively. The advantage of expressing fluorescence polarization as anisotropy is the additive nature of the latter. Differences in the efficiency of transmitting vertically and horizontally polarized light were corrected for by the factor $I_{0} / I_{90}$, determined by using horizontally rather than vertically polarized excitation light.

Varying the molar ratio of membrane phospholipid to probe from 500:1 to 100:1 did not affect the measured anisotropy values, indicating the absence of membrane perturbations by the probes. Anisotropy values were also unaltered by different amounts of membrane protein, ranging from $35 \mu \mathrm{g}$ to $100 \mu \mathrm{g}$ in a final volume of $2 \mathrm{ml}$ of $50 \mathrm{mM}$ Tris- $\mathrm{HCl}, \mathrm{pH}$ 7.4. Furthermore, anisotropy measurements in both control and modified membranes were stable from $30 \mathrm{~min}$ to $3 \mathrm{~h}$ after the addition of the probe. Therefore, membrane microviscosity was determined with a molar ratio of membrane phospholipid to probe of 200:1 and with $50 \mu \mathrm{g}$ of membranc protein per tube after $60 \mathrm{~min}$ of incubation at $25^{\circ} \mathrm{C}$.

\section{Ligand binding}

The equilibrium binding of radiolabeled opioids at $25^{\circ} \mathrm{C}$ was determined as previously described by Fischel and Medzihradsky (1981). The assay medium contained 150$200 \mu \mathrm{g}$ of membrane protein per tube. In experiments with $\left[{ }^{3} \mathrm{H}\right] \mathrm{U} 69,593$, the glass-fiber filters were pretreated with a $0.05 \%$ aqueous solution of polyethylenciminc, $\mathrm{pH} \mathrm{7.4,} \mathrm{to}$ reduce binding of the radiolabeled opioid to filters (Hampton et al., 1982). Specific binding of the radiolabeled ligands was determined in the absence and presence of an excess of the respective unlabeled ligand (2 $\mu M$ DAMGO, $5 \mu M$ DPDPE, $2 \mu M \mathrm{U} 69,593)$. Binding equilibrium was reached at $80 \mathrm{~min}, 60 \mathrm{~min}$, and $40 \mathrm{~min}$ for radiolabeled DAMGO, DPDPE, and U69,593, respectively.

\section{Data analysis}

The results on ligand binding were analyzed by the statistical program SYSTAT (Wilkinson, 1988) considering modcls of one and two binding sites (Remmers et al., 1990). The regression analysis was carried out with data from three to five replicate experiments. All the binding parameters shown in Table 1 are based on regression for which the distribution of residuals was not different from a normal distribution. The corresponding SEM values were obtained from the residual sum of squares, provided by the regression analysis. The data on membrane microviscosity were analyzed by the computer program GraphPad (ISI Software, Philadelphia, PA, U.S.A.), and are expressed as mean values and SEM. 


\section{RESULTS}

Initially, the modulation of membrane microviscosity by three $\mathrm{C}_{18}$ cis-monounsaturated FA and their respective methyl esters (Fig. 1) was investigated. The addition of equimolar amounts of FA or FAME to membranes from rat cortex caused a similar 7-10\% decrease in DPH fluorescence anisotropy, indicating a fluidization of the hydrophobic core of the membrane (Fig. 2). As shown with the charged fluorophores TMA-DPH and PA-DPH (Fig. 1), membrane modification by FA decreased microviscosity in the surface region of the membrane by $5-7 \%$. In contrast, following the addition of FAME, the fluidization of the membrane surface was only marginal. This distinct pattern of fluidization caused by the charged and methylated FA, respectively, was similar regardless of the position of unsaturation in the molecule (Fig. 2). Furthermore, in membranes from monkey brain cortex, oleic acid and methyl oleate decreased microviscosity at the core and surface regions of the membrane with a similar pattern and magnitude as that observed in membranes from rat cortex (data not shown). Actually, methyl oleate was even more potent in fluidizing the core region of monkey rather than rat membranes ( $14 \%$ and $9 \%$ decrease in anisotropy, respectively).

The reduction of membrane microviscosity by FA, both in the core and surface region of the membrane, was completely reversed following the addition of CHS. CHS was particularly effective in restoring the microviscosity of membranes initially fluidized by FA (Fig. 3). Once the normal level of microviscosity at the membrane surface was restored, further rigidification progressed at a slower rate, and in control membranes low concentrations of CHS had no effect. In contrast, CHS strongly increased the microviscosity in the core of both FA-treated and control membranes (Fig. 3).
In the modified membranes, ligand binding to opioid receptors was inhibited in strict correlation with the degree of achieved fluidization at the membrane surface. Accordingly, opioid binding was largely unaffected in membranes treated with FAME. On the other hand, the unsaturated FA inhibited opioid binding by a distinct pattern of $\delta>\mu \gg \kappa$, whereby the $\delta$ receptor, and to a lesser extent, the $\mu$ receptor, exhibited increasing sensitivity as the position of the double bond approached the carboxyl end of the molecule (Fig. 5). These results, obtained with one receptor-saturating concentration of radioligand, were confirmed by Scatchard analysis of opioid binding: free oleic acid at $0.5 \mu \mathrm{mol} / \mathrm{mg}$ of protein rendered the $B_{\max }$ of $\delta$ receptor binding undetectable, and considerably inhibited ligand interaction with the $\mu$ receptor (Fig. 6 and Table 1). On the other hand, in monkey brain membranes used to significantly measure $\kappa$-opioid binding, the concentration of oleic acid had to be raised twofold relative to that modulating $\delta$ and $\mu$ binding. But even at that concentration, only the $B_{\max }$, but not $K_{\mathrm{D}}$, of $\left[{ }^{3} \mathrm{H}\right] \mathrm{U} 69,593$ binding was affected. Furthermore, equimolar concentrations of elaidic acid, the trans isomer of oleic acid with diminished fluidizing properties (Remmers et al., 1990 and Fig. 4) was only marginally effective (Table 1). Methyl oleate did not significantly affect the parameters of ligand binding to any of the opioid receptors. Considering the low level binding of $\left[{ }^{3} \mathrm{H}\right] \mathrm{U} 69,593$ in rat brain (Clark et al., 1988), all experiments pertaining to the $\kappa$ opioid receptor were carried out in membranes from monkey brain cortex. It was ascertained that in these membranes the pattern of fluidization (Fig. 4) and inhibition of $\delta$-, $\mu$-, and $\kappa$-opioid binding by FA (Figs. 5 and 6 ) was similar to that observed in membranes from rat brain.

In addition to restoring the reduced membrane microviscosity caused by oleic acid (Figs. 3 and 4), the
MEMBRANE MODIFIERS

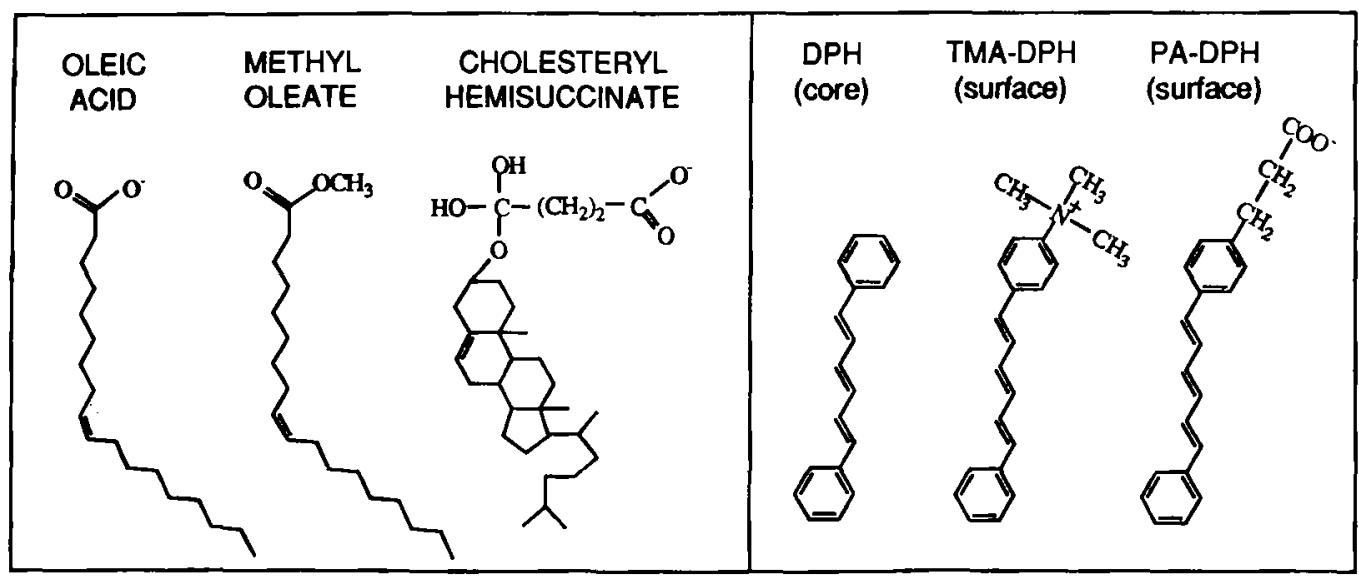

FIG. 1. Structural features of membrane modifiers and of fluidity probes. 
subsequent addition of CHS reversed the inhibition of ligand binding by approximately $40 \mathrm{fmol} / \mathrm{mg}$ of protein at the $\mu$ and $\kappa$ receptors, and by $90 \mathrm{fmol} / \mathrm{mg}$ of protein at the $\delta$-opioid receptor at which binding was initially abolished by treatment with FA alone (Fig. 6 and Table 1). After CHS treatment only the $K_{\mathrm{D}}$ of $\left[{ }^{3} \mathrm{H}\right] \mathrm{DPDPE}$ remained higher relative to the control value (Table 1). In untreated membranes the addition of CHS increased the $B_{\max }$ of $\delta$-, $\mu$-, and $\kappa$-opioids, by $38 \%, 25 \%$, and $23 \%$, respectively. In these membranes, as in those treated with FA, the $K_{\mathrm{D}}$ at the $\delta$ site was affected most (Table 1).

\section{DISCUSSION}

Using fluorescent probes to assess regional fluidization in brain membranes, the results of the present study implicate the microviscosity at the membrane surface in the modulation of opioid receptors. The inhibition of receptor binding by free and methylated FA was proportional to the ability of these compounds to decrease the microviscosity at the brain membrane surface. The inhibition at the $\delta$ and, to a lesser extent, $\mu$ receptor by FA increased as the position of the cis-unsaturated bond, a structural feature with strong fluidizing properties, moved closer to the carboxyl end of the molecule. Measurement of mem-

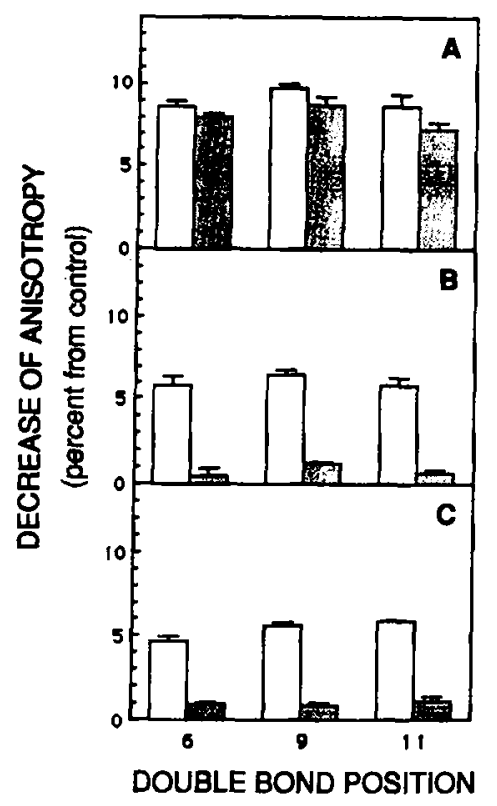

FIG. 2. Microviscosity of rat brain membranes modified by FA and their methyl esters. Synaptosomal membranes were modified by the addition of $0.5 \mu \mathrm{mol} / \mathrm{mg}$ of membrane protein of either petroselenic (cis- $\Delta^{6}$-octadecenoic) acid; oleic (c/s- $\Delta^{9}$-octadecenoic) acid; or cis-vaccenic (cis- $\Delta^{11}$-octadecenoic) acid ( $\square$ ), or their corresponding methyl esters (잠). After the incorporation of DPH (A), TMA-DPH (B), or PA-DPH (C) into control or modified membranes, fluorescence anisotropy was determined as described in Materials and Methods. Shown are the means and SEM of three to five experiments, each carried out in triplicate.

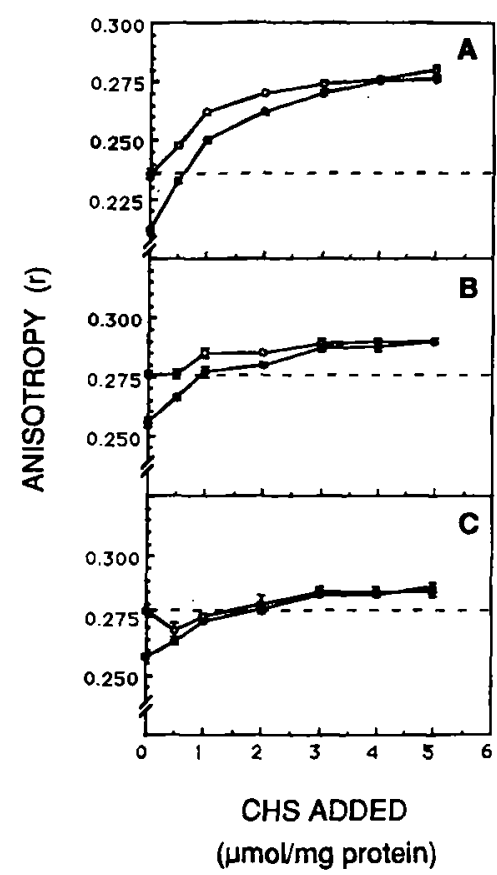

FIG. 3. Microviscosity of rat brain membranes modified by cholesterol. Control synaptosomal membranes $(O)$ and membranes initially treated with $0.5 \mu \mathrm{mol} / \mathrm{mg}$ of membrane protein of oleic acid $(\bullet)$ were modified by the addition of increasing concentrations of CHS as shown. Following incorporation of DPH (A), TMA-DPH (B), or PA-DPH (C), fluorescence anisotropy $(r)$ was determined as described in Materials and Methods. Shown are the means and SEM of three experiments, each carried out in triplicate.

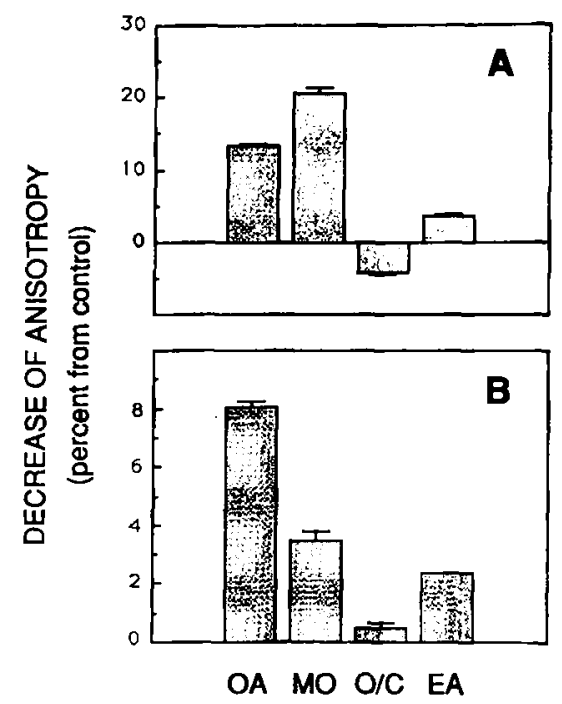

FIG. 4. Microviscosity of monkey brain membranes. Cortical membranes were modified by the addition of $1 \mu \mathrm{mol} / \mathrm{mg}$ of membrane protein of oleic acid (OA), methyl oleate (MO), elaidic acid (EA), or oleic acid followed by $3 \mu \mathrm{mol} / \mathrm{mg}$ of membrane protein of CHS $(O / C)$. After the incorporation of DPH (A) or TMA-DPH (B) into control or modified membranes, fluorescence anisotropy was determined as described in Materials and Methods. Shown are the means and SEM of three experiments, each carried out in triplicate. 


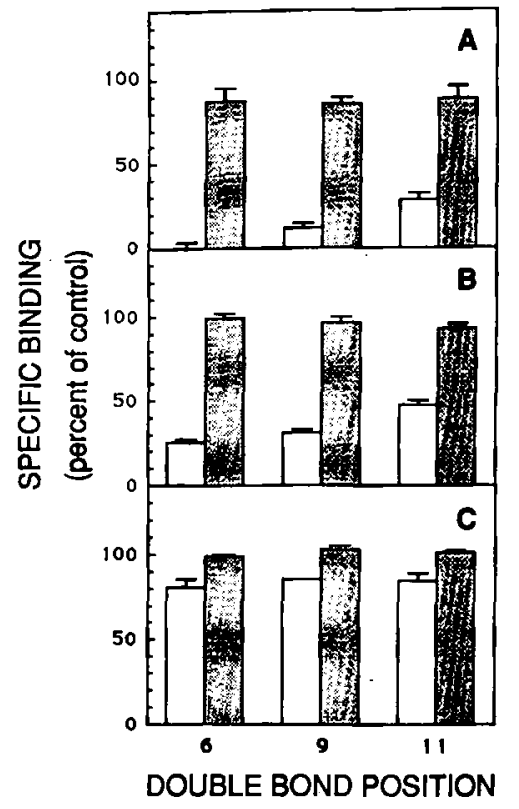

FIG. 5. Pattern of inhibition of opioid receptor binding following membrane modification. Synaptosomal membranes from rat brain were incubated with $0.5 \mu \mathrm{mol} / \mathrm{mg}$ of membrane protein of either petroselenic (cis- $\Delta^{6}$-octadecenoic) acid; oleic (cis- $\Delta^{9}$-octadecenoic) acid, or vaccenic (cis- $\Delta^{11}$-octadecenoic) acid ( $\square$ ), or their corresponding methyl esters (ㅂ). Subsequently, the specific binding of $\left[{ }^{3} \mathrm{H}\right]$ DPDPE (A), $\left[{ }^{3} \mathrm{H}\right] \mathrm{DAMGO}(\mathbf{B})$, or $\left[{ }^{3} \mathrm{H}\right] \cup 69,593$ (C) was determined at a fixed ligand concentration of 10-fold the respective $K_{D}$ value in untreated membranes. In identically modified membranes from monkey brain, the specific binding of tritiated DPDPE, DAMGO, and U69,593 was inhibited (in percent) $75.9 \pm 2.6,47.0 \pm 1.5$, and 15.3 \pm 0.3. Shown are the means and SEM of at least three experiments, each carried out in triplicate.

brane microviscosity with various probes has shown that the surface region of both natural (Viret and Leterrier, 1976) and synthetic (Chefurka et al., 1987) membrane bilayers is more rigid than the hydrophobic core region. As such, the membrane surface region is expected to have a more constraining effect on the positioning and conformation of receptors within the bilayer than the more fluid core. The negatively charged carboxyl group of free FA interacts by hydrogen bonding with the polar phospholipid headgroups (Ortiz and Gomez-Fernandez, 1987). Thus, fluidization of the membrane surface region by FA is likely to perturb some of the lipid headgroup-protein interactions required for the function of membrane proteins (Marsh, 1987). In contrast, fluidization of the membrane core by FAME may leave these interactions intact.

The $\delta$-opioid receptor was most sensitive to inhibition by FA: membrane treatment with oleic acid abolished $\left[{ }^{3} \mathrm{H}\right] \mathrm{DPDPE}$ binding, reduced the affinity and $B_{\max }$ of $\left[{ }^{3} \mathrm{H}\right]$ DAMGO, but significant effects at the $\kappa$ receptor required higher concentration of the FA. Still, the involvement of membrane fluidity in the inhibition of $\kappa$ receptor function by oleic acid was underlined by the attenuated effect of its trans enan- tiomer, elaidic acid (Table 1). Trans FA were previously shown to have a much smaller effect on membrane fluidization than their cis counterparts (Remmers et al., 1990). A similar pattern of opioid receptor sensitivity to membrane perturbation has previously been demonstrated: ethanol inhibited opioid receptor binding with a rank order of $\delta \geq \mu \gg \kappa$ (Hiller et al., 1983; Khatami et al., 1987). Although in these studies membrane microviscosity was not determined, an altered microenvironment of the receptor was implicated. Significant evidence for a role of membrane fluidity in the modulation of opioid receptors was provided by the ability of CHS to reverse
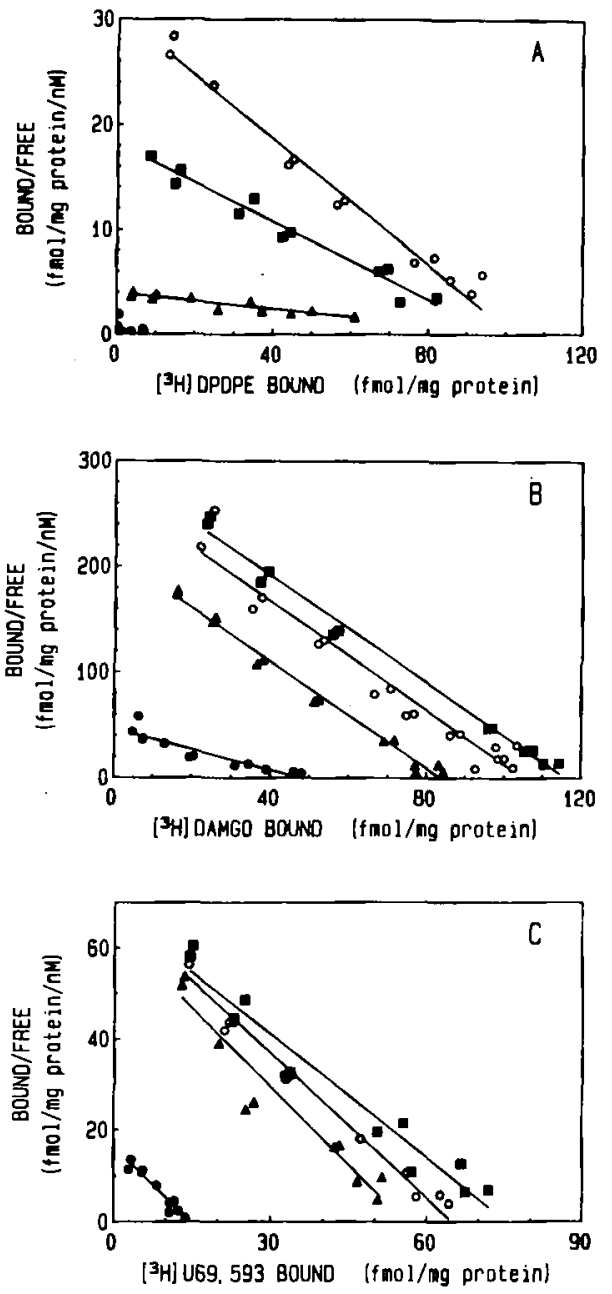

FIG. 6. Scatchard plots of opioid binding in modified brain membranes. Equilibrium binding of $\left[{ }^{3} \mathrm{H}\right] \mathrm{DPDPE}(\mathbf{A}),\left[{ }^{3} \mathrm{H}\right] \mathrm{DAMGO}(\mathbf{B})$, and $\left[{ }^{3} \mathrm{H}\right] \cup 69,593$ (C) was determined in control membranes $(\mathrm{O})$, and membranes modified with $0.5 \mu \mathrm{mol} / \mathrm{mg}$ of membrane protein (rat brain, $\mathrm{A}$ and $\mathrm{B}$ ) or $1 \mu \mathrm{mol} / \mathrm{mg}$ of membrane protein (monkey brain, C) of oleic acid $(\bullet)$ or methyl oleate $(\square)$, or with oleic acid (as above) followed by $3 \mu \mathrm{mol} / \mathrm{mg}$ of protein of cholesteryl hemisuccinate $(\boldsymbol{\Lambda})$. Shown are data points from a representative experiment. The binding parameters $K_{\mathrm{D}}$ and $B_{\max }$ were obtained by nonlinear regression analysis from data obtained in three experiments. The corresponding mean values and statistical information are listed in Table 1. 
TABLE 1. Parameters of opioid binding in modified and control brain membranes

\begin{tabular}{|c|c|c|c|c|}
\hline $\begin{array}{l}\text { Modifiers } \\
\text { added }\end{array}$ & $\begin{array}{c}\text { Amount added } \\
(\mu \mathrm{mol} / \mathrm{mg} \text { of protein })\end{array}$ & $\underset{(\mathrm{n} M)}{K_{\mathrm{D}}}$ & $\begin{array}{c}B_{\max } \\
\text { (fmol/mg of protein) }\end{array}$ & n \\
\hline \multicolumn{5}{|c|}{ Binding of $\left[{ }^{3} \mathrm{H}\right] \mathrm{DPDPE}$} \\
\hline None & & $3.52(0.33)$ & $97.7(8.1)$ & 45 \\
\hline $\mathrm{OA}$ & 0.5 & ND & ND & 42 \\
\hline MO & 0.5 & $5.99(1.09)$ & $90.0(17.0)$ & 44 \\
\hline CHS & 3.0 & $11.70(1.90)$ & $135.0(12.0)$ & 35 \\
\hline $\mathrm{OA} / \mathrm{CHS}$ & $0.5 / 3.0$ & $16.80(5.40)$ & $89.5(16.8)$ & 38 \\
\hline \multicolumn{5}{|c|}{ Binding of $\left[{ }^{3} \mathrm{H}\right] \mathrm{DAMGO}$} \\
\hline None & & $0.36(0.02)$ & $109 \quad(3.0)$ & 46 \\
\hline $\mathrm{OA}$ & 0.5 & $0.92(0.13)$ & $45.0(4.7)$ & 46 \\
\hline MO & 0.5 & $0.42(0.03)$ & $117 \quad(6.0)$ & 47 \\
\hline CHS & 3.0 & $0.35(0.02)$ & $136 \quad(4.0)$ & 42 \\
\hline $\mathrm{OA} / \mathrm{CHS}$ & $0.5 / 3.0$ & $0.40(0.02)$ & $84.7(2.2)$ & 40 \\
\hline \multicolumn{5}{|c|}{ Binding of $\left[{ }^{3} \mathrm{H}\right] \mathrm{U} 69,593$} \\
\hline None & & $0.91(0.08)$ & $60.2(3.3)$ & 41 \\
\hline $\mathrm{OA}$ & 1.0 & $0.84(0.15)$ & $17.5(1.9)$ & 38 \\
\hline MO & 1.0 & $1.07(0.06)$ & $72.0(2.9)$ & 42 \\
\hline CHS & 3.0 & $0.49(0.06)$ & $73.4(4.4)$ & 40 \\
\hline $\mathrm{OA} / \mathrm{CHS}$ & $1.0 / 3.0$ & $0.82(0.08)$ & $60.9(3.7)$ & 39 \\
\hline $\mathrm{EA}$ & 1.0 & $1.20(0.08)$ & $51.2(2.4)$ & 40 \\
\hline
\end{tabular}

The binding parameters at equilibrium were obtained from nonlinear regression analysis, fitting the data to a one-site model for ligand binding. Shown are parameter means and SEM values (in parentheses) computed from the total number of data points (n) obtained in three experiments depicted in Fig. 6. Membrane modification was carried out as described in Materials and Methods. OA, oleic acid; MO, methyl oleate; CHS, cholesteryl hemisuccinate; EA, elaidic acid. ND, not detectable.

both consequences of FA modification of brain membranes: decreased microviscosity and inhibition of ligand binding. The effect of CHS at the $\delta$ receptor was particularly striking: after being abolished in the fluidized membranes, $\left[{ }^{3} \mathrm{H}\right] \mathrm{DPDPE}$ binding was restored to control levels following CHS treatment. The elevated $K_{\mathrm{D}}$ of $\delta$-but not $\mu$ - or $\kappa$-opioid binding in CHS-treated membranes (Table 1) could reflect interference with ligand binding by the interaction of this negatively charged modifier with the cationic environment of the $\delta$ receptor (Schwyzer, 1986; Sargent et al., 1988). Furthermore, the proposal that the $\delta$ and $\mu$ sites reside in a cationic and anionic microenvironment, respectively, could explain the preferential targeting of the $\delta$ receptor by the negatively charged FA.

Lateral and vertical heterogeneity within a given membrane with respect to lipid composition, protein distribution, and physicochemical state contribute to the existence of membrane domains with different characteristics (Melchior, 1986; Treistman et al., 1987). Furthermore, specific interactions between membrane proteins and certain membrane lipids (Latruffe et al., 1986; Marsh, 1987) define a specific lipid boundary layer around functional membrane proteins such as the nicotinic acetylcholine receptor (Jones et al., 1988). Attempts to reconstitute ligand binding to the partially purified $\mu$ - (Hasegawa et al., 1987 ) and $\delta$ - (Scheideler and Zukin, 1990) opioid receptors have indicated requirements for specific phospholipids. It is reasonable, therefore, to consider the existence of different local domains or boundary layers for the distinct types of opioid receptors in brain membranes. Interestingly, both ethanol (Wood et al., 1989) and cis-unsaturated fatty acids (Klausner et al., 1980; Ortiz and Gomez-Fernandez, 1987) have greater fluidizing effects on fluid-like regions than gellike regions when added to membrane preparations. Considering the similar effects of these two fluidizers on opioid receptor binding, the lipid domains in which $\mu$ and $\delta$ receptors reside may be more fluid than those in which $\kappa$ receptors exist. Notably, studies with bivalent ligands have indicated a physical complex between some $\mu$ and $\delta$ receptors (Schoffelmeer et al., 1990). Although ethanol was reported to have ordering effects on neuronal membranes at very low concentrations and elevated temperatures (Hitzemann et al., 1986) or following chronic administration (Harris et al., 1984), acutely and under the experimental conditions of the present study ethanol fluidized the membrane surface (Harris et al., 1984; Harris and Bruno, 1985).

Changes in lipid composition and membrane fluidity were shown to affect the function of membrane proteins by affecting their conformational states (Fong and McNamee, 1987; Aloia et al., 1988). For example, membrane fluidization by either unsaturated FA or ethanol inhibited the transition to the $\mathrm{K}^{+}$-sensitive conformation of $\mathrm{Na}^{+}, \mathrm{K}^{+}$-ATPase (Swann, 1984), and a decrease in membrane fluidity elicited conformational changes in the lipid-buried subunit of mitochondrial $\mathrm{H}^{+}$-ATPase that were transmitted to the aqueous subunit of the enzyme (Zhang and Yang, 1989). Thus, the effects of FA and cholesterol described in the present study could reflect the 
distortion and restoration, respectively, of opioid receptor conformation that is optimal for ligand binding. Furthermore, according to this concept, the strong inhibition of opioid receptor binding by a high concentration of cholesterol, observed previously (Heron et al., 1981), can be the consequence of displacement by the sterol of essential lipids in the boundary layer surrounding the receptor.

The seemingly high concentration of CHS required to maximally reverse inhibition of opioid binding by cis-monounsaturated FA is likely to be due to a shortcoming of the applied methodology: the measurement of membrane microviscosity with probes such as DPH, TMA-DPH, and PA-DPH does not necessarily reflect fluidity changes occurring in the microenvironment of the opioid receptors. Although bulk membrane fluidity could have returned to control levels, the fluidity sensed by the opioid receptors may still be greater than that in control membranes. At higher levels of cholesterol, whose compartmentalization in membranes was described (Leibel et al., 1987), its concentration in various membrane domains will increase, thus reversing fluidity in the lipid boundary layer of the receptors and, concomitantly, restoring opioid binding. Further studies with membrane modification (Medzihradsky, 1989) will be needed to specifically alter the composition and physicochemical property of the boundary layer, the lipidprotein interface that is likely to have a strong effect on the conformation and function of opioid receptors.

Numerous physiological conditions have been shown to modulate the lipid composition and fluidity of biological membranes. These include diet (McMurchie, 1988), development (Hitzemann and Harris, 1984), and aging (Shinitzky, 1987). In addition, drug administration (Heron et al., 1982) and various pathological conditions have resulted in altered membrane content of lipids and cholesterol (c.g., Aloia and Boggs, 1985). For example, in experimentally induced cerebral ischemia (Yoshida et al., 1983) significant increases in the concentration of free FA in brain were described. Therefore, the ability of FA and cholesterol to alter membrane microviscosity and differentially affect ligand binding to the $\delta$-, $\mu$-, and $\kappa$-opioid receptors may have significant implications for the modulation of opioid action in vivo.

Acknowledgment: We thank Ms. Becky McLaughlin for excellent secretarial assistance in preparing the manuscript. This work was supported by USPHS grant DA04087.

\section{REFERENCES}

Aloia R. C. and Boggs J. M., cds (1985) Membrane Fluidity in Biology, Vol. 3: Disease Processes. Academic Press, New York.

Aloia R. C., Curtain C. C., and Gordon L. M., eds (1988) Advances in Membrane Fluidity, Vol. 2: Lipid Domains and the Relationship to Membrane Function. Alan R. Liss, New York.
Cahill A. L. and Medzihradsky F. (1976) Interaction of central nervous system drugs with synaptosomal transport processes. Biochem. Pharmacol. 25, 2257-2264.

Carruthers A. and Melchior D. L. (1986) How bilayer lipids affect membrane protein activity. Trends Biochem. Sci. 11, 331335.

Chefurka W., Chatelier R. C., and Sawyer W. H. (1987) Perturbation of phospholipid bilayers by DDT. Biochim. Biophys. Acta 896, 181-186.

Childers S. R. and LaRiviere G. (1984) Modification of guanine nucleotide-regulatory components in brain membranes. II. Relationship of guanosine 5'-triphosphate effects in opiate receptor binding and coupling receptors with adenylate cyclase. J. Neurosci. 4, 2764-2771.

Clark M. J., Carter B. D., and Medzihradsky F. (1988) Selectivity of ligand binding to opioid receptors in brain membranes from the rat, monkey and guinea pig. Eur. J. Pharmacol. 148, 343351.

Fischel S. V. and Medzihradsky F. (1981) Scatchard analysis of opiate receptor binding. Mol. Pharmacol. 20, 269-279.

Fong T. M. and McNamee M. G. (1987) Stabilization of acetylcholine receptor secondary structure by cholesterol and negatively charged phospholipids in membranes. Biochemistry 26, 38713880 .

Hampton R. Y., Medzihradsky F., Woods J. H., and Dahlstrom P. J. (1982) Stereospecific binding of $\left[{ }^{3} \mathrm{H}\right]$-phencyclidine in brain membranes. Life Sci. 30, 2147-2154.

Harris R. A. and Bruno P. (1985) Membrane disordering by anesthetic drugs: relationship to synaptosomal sodium and calcium fluxes. $J$. Neurochem. 44, 1274-1281.

Harris R. A., Baxter D. M., Mitchel M. A., and Hitzemann R. J. (1984) Physical properties and lipid composition of brain membranes from ethanol tolerant-dependent mice. Mol. Pharmacol. 25, 401-409.

Hasegawa J.-I., Loh H. H., and Lee N. M. (1987) Lipid requirement for $\mu$ opioid receptor binding. $J$. Neurochem. 49, 1007-1012.

Hazum E., Chang K.-J., and Cuatrecasas P. (1980) Cluster formation of opiate (enkephalin) receptors in ncuroblastoma cells: differences between agonists and antagonists and possible relationships to biological functions. Proc. Natl. Acad. Sci. USA 77, 3038-3041.

Heron D., Israeli M., Hershkowitz M., Samuel D., and Shinitzky M. (1981) Lipid-induced modulation of opiate receptors in mouse brain membranes. Eur. J. Pharmacol. 72, 361-364.

Heron D., Shinitzky M., Zamir N., and Samuel D. (1982) Adaptive modulations of brain membrane fluidity in drug addiction and denervation supersensitivity. Biochem. Pharmacol. 31, 24352438.

Hiller J. M., Angel L. M., and Simon E. J. (1983) Characterization of the selective inhibition of the $\delta$ subclass of opioid binding sites by alcohols. Mol. Pharmacol. 25, 249-255.

Hitzemann R. J. and Harris R. A. (1984) Developmental changes in synaptic membrane fluidity: a comparison of 1,6-diphenyl1,3,5-hexatriene (DPH) and 1-[4-(trimethyl-amino)phenyl]-6phenyl-1,3,5-hexatriene (TMA-DPH). Brain Res. 316, $113-$ 120.

Hitzemann R. J., Schueler H. E., Graham-Brittain C., and Kreishman G. P. (1986) Ethanol-induced changes in neuronal membrane order. An NMR study. Biochim. Biophys. Acta 859, $189-197$.

Ho W. K. K. and Cox B. M. (1982) Reduction of opioid binding in neuroblastoma $\times$ glioma cells grown in medium containing unsaturated fatty acids. Biochim. Biophys. Acta 688, 211-217.

Jones O. T., Eubanks J. H., Earnest J. P., and McNamee M. G. (1988) A minimum number of lipids are required to support the functional properties of the nicotinic acetylcholine receptor. Biochemistry 27, 3733-3742.

Khatami S., Hoffman P. L., Shibuya T., and Salafsky B. (1987) Selective effects of ethanol on opiate receptor subtypes in brain. Neuropharmacology 26, 1503-1507.

Klausner R. D., Kleinfeld A. M., Hoover R. L., and Karnovsky M. J. (1980) Lipid domains in membranes. Evidence derived 
from structural perturbations induced by free fatty acids and lifetime heterogeneity analysis. J. Biol. Chem. 255, 12861295.

Latruffe N., Berrez J.-M., and El Kebbaj M. S. (1986) Lipid-protein interaction in biomembranes studied through the phospholipid specificity of $\mathrm{D}-\beta$-hydroxybutyrate dehydrogenase. Biochimie 68, 481-491.

Lazar D., Goldsmith A., and Medzihradsky F. (1991) Inhibition of opioid receptor binding involving membrane surface fluidization: reversal by cholesterol, in Abstracts, Third IBRO World Congress of Neuroscience, Montreal. P60.11

Lcibel W. S., Firestone L. L., Legler D. C., Braswell L. M., and Miller K. W. (1987) Two pools of cholesterol in acetylcholine receptor-rich membranes from Torpedo. Biochim. Biophys. Acta 897, 249-260.

Lin H.-K. and Simon E. J. (1978) Phospholipasc A inhibition of opiate receptor binding can be reversed by albumin. Nature 271, 383-384.

Lowry O. H., Rosebrough N. J., Farr A. L., and Randall R. J. (1951) Protein measurement with the Folin phenol reagent. J. Biol. Chem. 193, 265-275.

Marsh D. (1987) Selectivity of lipid-protein interactions. J. Bioenerget. Biomembr. 19, 677-689.

Maruyama M., Sugino H., Akita K., and Hatanaka H. (1987) Binding characteristics of $\left[{ }^{3} \mathrm{H}\right]$ opioid ligands to active opioid binding sites solubilized from rat brain membranes by glycodeoxycholate and $\mathrm{NaCl}$ : the recovery of binding activity by dilution. Brain Res. 401, 14-22.

McGee R. Jr. and Kenimer J. G. (1982) The effects of exposure to unsaturated fatty acids on opiate receptors, prostaglandin $E_{1}$ receptors, and adenylate cyclase activity of neuroblastoma $\times$ glioma hybrid cells. Mol. Pharmacol. 22, 360-368.

McMurchie E. J. (1988) Dietary lipids and the regulation of membrane fluidity and function, in Physiological Regulation of Membrane Fluidity (Aloia R. C., Curtain C. C., and Gordon L. M., eds), pp. 189-237. Alan R. Liss, New York.

Medzihradsky F. (1989) Modulation of opioid receptor mechanisms by membrane lipids: an investigative approach. $A d v$. Biosci. 75, 41-44.

Melchior D. L. (1986) Lipid domains in fluid membranes: a quickfreeze differential scanning calorimetry study. Science 234, $1577-1580$.

Ortiz A. and Gomez-Fernandez J. C. (1987) A differential scanning calorimetry study of the interaction of free fatty acids with phospholipid membranes. Chem. Phys. Lipids 45, 75-91.

Remmers A. E., Nordby G. L., and Medzihradsky F. (1990) Modulation of opioid receptor binding by $c i s$ and trans fatty acids. $J$. Neurochem. 55, 1993-2000.

Sargent D. F., Bean J. W., and Schwyzer R. (1988) Conformation and orientation of regulatory peptides on lipid membranes. Key to the molecular mechanism of receptor selection. Biophys. Chem. 31, 183-193.

Scheideler M. A. and Zukin R. S. (1990) Reconstitution of solubilized $\delta$-opiate receptor binding sites in lipid vesicles. $J$. Biol. Chem. 265, 15176-15182.

Schiller P. W., Nguyen T. M.-D., Chung N. N., and Lemieux C. (1989) Dermorphan analogues carrying an increased positive net charge in their "message" domain display extremcly high $\mu$ opioid receptor selectivity. J. Med. Chem. 32, 698-703.

Schoffelmeer A. N. M., Yao Y., and Simon E. J. (1990) Cross-linking of ${ }^{12 s} \mathrm{I}-\beta$-endorphin to rat striatal $\mu$-and $\delta$-opioid receptors under physiological conditions: evidence for an opioid receptor complex. Prog. Clin. Biol. Res. 328, 105-108.

Schwyzer R. (1986) Molecular mechanism of opioid receptor selection. Biochemistry 25, 6335-6342.

Shinitzky M. (1987) Patterns of lipid changes in membranes of the aged brain. Gerontology 33, 149-154.

Swann A. C. (1984) Free fatty acids and $\left(\mathrm{Na}^{+}, \mathrm{K}^{+}\right)$-ATPase: effects on cation regulation, enzyme conformation, and interactions with ethanol. Arch. Biochem. Biophys. 233, 354-361.

Tandon N., Harmon J. T., Rodbard D., and Jamieson G. A. (1983) Thrombin receptors define responsiveness of cholesterol-modified platelets. J. Biol. Chem. 258, 11840-11845.

Treistman S. N., Moynihan M. M., and Wolf D. E. (1987) Influence of alcohols, temperature, and region on the mobility of lipids in neuronal membrane. Biochim. Biophys. Acta 898, 109-120.

Viret J. and Leterrier F. (1976) A spin label study of rat brain membranes. Effects of temperature and divalent cations. Biochim. Biophys. Acta 436, 811-824.

Viret J., Daveloose D., and Leterrier F. (1990) Modulation of the activity of functional membrane proteins by the lipid bilayer fluidity, in Membrane Transport and Information Storage (Aloia R. C., Curtain C. C., and Gordon L. M., eds), pp. 239253. Alan R. Liss, New York.

Wilkinson L. (1988) SYSTAT: The System for Statistics. SYSTAT Inc., Evanston, IL.

Wood W. G., Gorka C. G., and Schroeder F. (1989) Acute and chronic effects of ethanol on transbilayer membrane domains. J. Neurochem. 52, 1925-1930.

Yoshida S., Inoh S., Asano T., Sano K., Shimasaki H., and Ueta N. (1983) Brain free fatty acids, edema, and mortality in gerbils subjected to transient, bilateral ischemia, and effect of barbiturate anesthesia. $J$. Neurochem. 40, 1278-1286.

Zhang X. F. and Yang F. Y. (1989) Further study on the role of $\mathrm{Mg}^{2+}$ in lipid-protein interaction in reconstituted porcine heart mitochondrial $\mathrm{H}^{+}$-A TPase. Biochim. Biophys. Acla 976, $53-62$. 